\title{
Práticas intraempreendedoras na gestão pública: um estudo de caso na Embrapa
} ÉDIS MAFRA LAPOLLI I e ROBERTO KERN GOMES II

\section{Introdução}

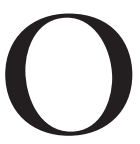

ESTUDO de produtividade, qualidade e eficiência no setor público normalmente encontra barreiras, seja por parte dos servidores, devido a questões ideológicas e sindicais, seja por parte dos entes políticos envolvidos. Se, por um lado, os servidores não se sentem impelidos a aceitar riscos, inovar e empreender; por outro, os agentes políticos também não se interessam em alterar esse estado de coisas (Tosterud, 2000; Gomes; Lapolli, 2014).

Nesse contexto, a administração pública enfrenta atualmente um problema bastante complexo, qual seja: os servidores, sobretudo aqueles que ocupam cargos de gestão, estão, na maior parte de seu tempo, envolvidos com tarefas e questões puramente burocráticas. Lima $(2007$, p.49) afirma que "a cultura burocrática é um traço indelével que, até onde a vista alcança, tem marcado a história da administração pública brasileira". Esse estado de coisas acaba por engendrar uma perda dos resultados que os órgãos da administração pública deveriam apresentar em favor da sociedade. Dessa forma, a gestão das instituições públicas, centralizada e rígida, como previam os críticos da Teoria Burocrática weberiana, tornou-se um fim em si mesma. Assim, como uma disfunção da burocracia, o serviço fica orientado aos processos e às tarefas, em vez de ter foco nos resultados e nos clientes (Matias-Pereira, 2012; Gomes; Lapolli, 2014).

É notável, nesse contexto, que o setor público, devido a esse alto grau de burocratização, inibe uma cultura empreendedora baseada na inovação, autonomia e flexibilidade (Valadares; Emmendoerfer, 2015).

Da mesma forma, todavia, que o intraempreendedorismo é visto como a mola propulsora da inovação e do uso das melhores práticas de gestão na iniciativa privada, entende-se que essa força possa ser aproveitada também no setor público. Notadamente, a Empresa Brasileira de Pesquisa Agropecuária (Embrapa) é uma organização pública que tem se destacado por suas pesquisas e pela sua inovação. Assim, sua unidade de suínos e aves, localizada na cidade de Concórdia, Santa Catarina, foi utilizada como laboratório para este artigo com o fito de aprofundar os estudos da temática do intraempreendedorismo e responder a seguinte pergunta de pesquisa: Quais práticas intraempreendedoras são utilizadas na Embrapa e quais as dificuldades de sua aplicação? 


\section{Fundamentação teórica}

Vários estudos ao redor do mundo apontam que continua crescendo, nos últimos anos, o interesse pelo empreendedorismo, especialmente na academia e setores governamentais. Tais estudos apontam que é definitivamente crucial fomentar o espírito empreendedor entre os jovens, uma vez que o desenvolvimento de novos negócios suporta a prosperidade de qualquer país, especialmente os em desenvolvimento (Pihie; Bagheri; Sani, 2012; Olszewska, 2014).

Nesse contexto, é importante salientar que a inovação e o espírito empreendedor, aspectos indissociáveis do empreendedorismo, despontam como as principais práticas para se sobreviver na era do conhecimento. Essa capacidade de inovação é proveniente das pessoas e se manifesta no interior das organizações existentes, dando forma ao fenômeno do Intraempreendedorismo. Joseph Schumpeter, que, na primeira metade do século XX, se destacou pela associação do empreendedorismo com a inovação, afirmava que o empreendedor pode também inovar dentro de negócios já existentes, sendo possível ser empreendedor dentro de empresas já constituídas. Assim, Schumpeter (1985) já previa a existência do empreendedor corporativo, ou intraempreendedor, termo que viria a ser criado anos mais tarde por Pinchot, conforme será apresentado a seguir.

\section{Intraempreendedorismo}

O termo intraempreendedorismo foi criado por Gifford Pinchot III no final da década de 1970, para caracterizar as ações das empresas no sentido de criar um ambiente de incentivo à inovação, à aceitação de riscos e à criatividade dentro das empresas existentes.

Pinchot (1989) percebeu que, em muitas empresas, há trabalhadores com as características e comportamentos empreendedores, mas que, por razões diversas, preferem continuar trabalhando nessas organizações. Para o autor, esses trabalhadores são os intraempreendedores, que são todos aqueles que assumem a responsabilidade pela criação de inovações de qualquer espécie dentro de uma organização. Esses empregados intraempreendedores são considerados importantes motores de inovação e renovação estratégica dentro das empresas.

Nas últimas décadas, com o aumento da competitividade entre as organizações, o clima de constantes mudanças econômicas e organizacionais, além do surgimento da era do conhecimento, o comportamento empreendedor tornou-se uma exigência entre as características pessoais dos profissionais que atuam nas empresas (Wyk; Adonisi, 2012; Baruah; Ward, 2014). O empreendedorismo, portanto, "passou a ser uma competência básica para o alcance dos objetivos dos atores presentes no mercado" (Valadares; Emmendoerfer, 2015, p.84) e condição para a sobrevivência, melhoria de performance e crescimento das organizações (Goodale et al., 2011; Antoncic; Antoncic, 2011).

Assim, o conceito atual de empreendedor não mais apenas abarca aquele sujeito que abre um negócio próprio, mas inclui também os empregados empreendedores, que desenvolvem e realizam visões em prol da melhoria dos proces- 
sos, fazendo que a empresa melhore seu desempenho (Pessoa; Oliveira, 2006; Valsania; Moriano; Molero, 2014).

\section{O intraempreendedorismo no setor público}

Quando se fala em empreendedorismo, dificilmente o interlocutor remeterá seu pensamento ao serviço público. Isso se deve ao fato de que a gênese da palavra tem a ver com a capacidade de assumir riscos, inovar, ter uma ideia e capitalizar sobre ela, gerando lucros sobre o negócio resultante, atitudes pouco comuns no ambiente público. Zahra e Wright (2011) afirmam, inclusive, que para que o empreendedorismo possa influenciar a prática gerencial das políticas públicas, é necessário haver uma mudança substantiva no foco, conteúdo e métodos de pesquisa sobre empreendedorismo.

Assim, essa noção de que há uma forte ligação entre o setor privado e o empreendedorismo resultou no fato de que, em muitos casos, o fenômeno do empreendedorismo no setor público seja negligenciado (Sundin; Tillmar, 2008).

Em que pesem, todavia, essas ponderações, cresceram nos últimos anos os estudos acerca do empreendedorismo público como forma de gerar mais inovação e qualidade na prestação dos serviços aos cidadãos (Kearney; Hisrich; Roche, 2007, 2010; Meynhardt; Diefenbach, 2012; Kearney; Morris, 2015).

Valadares et al. (2012), por sua vez, acreditam que o interesse pelo tema se deve ao fato de que está em curso um processo de modernização nas instituições públicas, que tem sido associado a noções comportamentais e gerenciais que trazem consigo conceitos e práticas que eram próprias e restritas às organizações empresariais privadas.

\section{Práticas intraempreendedoras}

As práticas intraempreendedoras são ações desenvolvidas pelas organizações e pelos seus colaboradores no sentido de facilitar que o fenômeno do empreendedorismo corporativo aflore dentro dessas organizações (Hashimoto, 2012).

Nesse contexto, os gestores devem ter em mente a importância de fatores como a orientação para o mercado, a flexibilidade e satisfação no trabalho no planejamento de estratégias e práticas para avançar o empreendedorismo corporativo (Wyk; Adonisi, 2012). Assim, a seguir apresentam-se as principais práticas encontradas durante o processo de revisão da literatura:

\section{- Prática de reconhecimento dos intraempreendedores}

Para que a ação intraempreendedora seja eficaz, cabe ao nível estratégico da organização desenvolver políticas de apoio e reconhecimento do profissional que se diferencia dos demais pelas suas ações de cunho empreendedor. Essa necessidade se deve ao fato de que, segundo Pessoa e Oliveira (2006, p.512), “o intraempreendedor tem a necessidade de reconhecimento por parte de seus superiores e pela própria sociedade, vontade de aumentar o status e de ser respeita- 
do pelos amigos e pela família”. Nesse contexto, ações que estimulem a criação de programas de recompensa e reconhecimento, além de facilitar o feedback aos profissionais que inovam e empreendem na organização, são boas práticas apontadas pelas autoras para aumentar o nível de intraempreendedorismo nas organizações.

Esse reconhecimento não deve, contudo, ser somente verbal ou simbólico. Assim, as empresas devem fornecer oportunidades de crescimento pessoal e desenvolvimento para seus empregados, além de garantir que seus funcionários sejam pagos de forma justa pelo seu trabalho (Antoncic; Antoncic, 2011).

\section{- Práticas para fomentar a criatividade e a inovação}

Acerca das melhores práticas, Sixsmith e Mooney (2012) também citam que fomentar a criatividade dos funcionários, a inovação na organização e a liderança dos gestores são práticas empresariais que podem levar a uma maior probabilidade de produzir resultados transformacionais na organização. A criatividade e a inovação podem ser estimuladas na medida em que a organização faça o possível para que os funcionários trabalhem em tarefas desafiadoras e interessantes (Antoncic; Antoncic, 2011).

Kuratko, Hornsby e Covin (2014, p.39) corroboram a ideia, afirmando que a organização que deseja criar um ambiente que conduza ao comportamento empreendedor, deverá seguir cinco importantes dimensões, quais sejam: garantia de apoio da alta direção, garantir autonomia aos trabalhadores, fornecer recompensas ao comportamento empreendedor, disponibilizar tempo e flexibilizar as fronteiras organizacionais.

\section{- Prática de comunicação}

Outra prática importante para estimular o intraempreendedorismo é a política de boa e constante comunicação com os empregados. Nesse sentido, Pessoa e Oliveira (2006) recomendam que a empresa deve adotar ações de forma a aumentar a participação dos funcionários, tais como uma maior disseminação de informações. Portanto, é fundamental que os objetivos e estratégias, além dos resultados alcançados, sejam informados constantemente, de maneira que todos tenham conhecimento da situação da empresa e do que pode ser feito para contribuir mais efetivamente. É preciso, finalmente, que os dirigentes “aprovem o comportamento empreendedor e reconheçam a importância da proatividade e da inovação em suas organizações", de modo que a inovação e o espírito empreendedor estejam disseminados por toda a empresa (Pessoa; Oliveira, 2006, p.517).

Antoncic e Antoncic (2011) também dão valor à comunicação e afirmam que é importante que os líderes e gestores compartilhem informações relevantes com a sua equipe de subordinados, de tal forma que eles tenham conhecimento da efetividade, sucesso ou fracasso das implementações e inovações ocorridas na organização. 


\section{- Prática de liberdade de ação}

Kuratko, Hornsby e Covin $(2014$, p.38) apontam a liberdade e a "quebra de regras" como boas práticas que devem ser incentivadas no sentido de se buscar o comportamento empreendedor dos funcionários. Para os autores, "para que o empreendedorismo corporativo floresça em empresas estabelecidas, é necessário que os indivíduos estejam livres para perseguir ações e iniciativas, a despeito das regras organizacionais" (ibidem).

Antoncic e Antoncic (2011) chamam essa liberdade de ação de flexibilidade. Para os autores, as empresas devem ser flexíveis em resposta a mudanças e procurar continuamente fazer melhorias nos processos. Assim, um número excessivo de procedimentos formais na execução de tarefas deve ser evitado, dando liberdade aos empregados para inovarem e proporem novas soluções para os problemas da empresa.

\section{- Prática de tolerância a erros}

A tolerância a erros também é apontada como uma prática que incentiva o intraempreendedorismo. Nesse contexto, quando os gerentes percebem que o ambiente institucional tem uma boa tolerância para riscos e erros, intrínsecos de toda inovação, eles sentem-se mais abertos à mudança dos modelos de orientação estratégica da organização, o que facilita o comportamento empreendedor (Haro; Correa; Pozo, 2011).

Pinchot $(1989$, p.17l) também acredita na tolerância a erros como ferramenta de auxílio à inovação quando afirma que a inovação "não pode ser conseguida sem riscos e erros". Para o autor, "mesmo as inovações bem-sucedidas começam geralmente com enganos e falsos começos".

\section{Dificuldades para o intraempreendedorismo público}

Após avaliar os diversos textos que tratam acerca do empreendedorismo no setor público, é possível inferir que a tarefa de incentivar o comportamento intraempreendedor no setor público é bastante complexa. Isso talvez se deva ao fato de ser tal setor extremamente burocrático. A esse respeito, tem-se que "o contexto do setor público, por ter um alto grau de burocratização, inibe uma cultura empreendedora baseada na inovação e também na autonomia e flexibilidade" (Valadares; Emmendoerfer, 2015, p.86).

Ainda acerca das dificuldades, Sadler (2000) aponta que a literatura que trata do empreendedorismo do setor público demonstra que algumas características tradicionais do ambiente público servem de inibição ao empreendedorismo corporativo. $\mathrm{O}$ autor descreve uma série dessas características, tais como: processos burocráticos; falta de concorrência; falta de controle de recursos; regulação e prestação de contas em massa; medição dos insumos, em vez de entregas; multiplicidade e ambiguidade de metas; necessidade permanente de consulta com as partes interessadas antes da tomada de decisão; intromissão política na gestão; políticas salariais e de funcionários restritivas; 
tendências de aversão ao risco; sistemas de recompensa/punição distorcidas ou inexistentes.

Assim, vê-se que a literatura apresenta diversas práticas, mas também as dificuldades de se implantar uma cultura intraempreendedora nas organizações públicas, de modo que será importante verificar como esses fatores ocorrem na organização pesquisada.

\section{Procedimentos metodológicos}

O presente artigo pode ser classificado como um trabalho de pesquisa aplicada, do tipo exploratória, pois exige do pesquisador, num primeiro momento, a familiarização com a realidade investigada e permite ao investigador aumentar sua experiência a respeito de determinado problema (Gil, 1999; Triviños, 2012). É ainda uma pesquisa descritiva, porque propõe descobrir, com a precisão possível, a frequência com que um fenômeno ocorre, sua relação e conexão com outros, sua natureza e características, além de tentar aprofundar o conhecimento de determinada realidade (Severino, 1985; Triviños, 2012). Por fim, do ponto de vista dos procedimentos técnicos do estudo, foi desenvolvida uma revisão de literatura e um estudo de caso na Empresa Brasileira de Pesquisa Agropecuária, com aplicação de entrevista semiestruturada, na segunda metade do ano 2016 , com os principais gestores da organização ( $1^{\circ}$ e $2^{\circ}$ escalões $)$, descritos aqui como E1, E2, E3, E4, E5, E6, E7 e E8.

\section{Caracterização da organização selecionada}

A Empresa Brasileira de Pesquisa Agropecuária (Embrapa), vinculada ao Ministério da Agricultura, Pecuária e Abastecimento, foi fundada em $1973 \mathrm{com}$ o objetivo de impulsionar o desenvolvimento agrícola nacional, de forma sustentável, por meio da geração de conhecimento e soluções tecnológicas que levassem o Brasil à autossuficiência na produção de alimentos e fibras e alavancassem seu potencial exportador (Embrapa, 2015).

Para atingir esse objetivo, além das unidades do Brasil, a Embrapa atua em todos os continentes, por meio de cooperação científica, cooperação técnica e de negócios tecnológicos.

Em Santa Catarina, a Embrapa é representada pela Embrapa Suínos e Aves, que fica localizada na cidade de Concórdia, no oeste do estado. Ela é uma das 47 Unidades Descentralizadas da Empresa e foi criada em 13 de junho de 1975, contando atualmente com 211 colaboradores, sendo 51 pesquisadores, 55 analistas, 37 técnicos e 68 assistentes. Segundo dados documentais da empresa, publicados em seu site, a Embrapa Suínos e Aves tem como missão "viabilizar soluções de pesquisa, desenvolvimento e inovação para a sustentabilidade da suinocultura e avicultura em benefício da sociedade brasileira".

\section{Apresentação e discussão dos dados}

Esta etapa tem a finalidade de apresentar as práticas intraempreendedoras que são utilizadas pela Embrapa Suínos e Aves e que têm garantido sua posição 
de destaque como uma organização de pesquisa inovadora e de excelência. Tem ainda o intuito de apresentar quais dificuldades foram apontadas pelos entrevistados para se ter e manter uma cultura que incentive o intraempreendedorismo como protagonista da inovação e criatividade na organização.

\section{Práticas intraempreendedoras na Embrapa}

- Estímulo ao comportamento intraempreendedor através de exemplos e desafios, recompensando o comportamento diferenciado

O empreendedor é movido por desafios e, além de contagiar o ambiente, é contagiado por ele. Ao serem questionados sobre como seria possível estimular o comportamento empreendedor e se isso ocorria na empresa, todos os entrevistados afirmaram ser possível esse estímulo e que isso ocorria na empresa. As formas de estimular tal comportamento, ainda segundo os entrevistados, variam e podem ser através de feedback, apoio financeiro, reconhecimento do comportamento diferenciado, incentivo à inovação, dentre outros. Todavia, a maior frequência das respostas apresentou o exemplo como forma de maior estímulo ao intraempreendedorismo. Finalmente, o fato de se sentir desafiado, questão de grande interesse do intraempreendedor, também foi apontado como forma de incentivo, conforme mostram os fragmentos a seguir.

E6 Eu acho que é possível estimular com exemplos. [...]. Além disso, a humildade e fazer as coisas em vez de só falar [...]. Então o negócio é fazer e dar o exemplo. Além disso, eu acho que as chefias têm que apoiar o comportamento diferenciado do funcionário, porque isso dá mais motivação.

E8 Eu acredito que é possível estimular através do reconhecimento pessoal e financeiro. [...] Agora o que eu acho que também incentiva bastante é o fato de a gente ser movido por desafios. Eu gosto de ter um desafio.

Ainda acerca do reconhecimento, todos os entrevistados afirmaram que são reconhecidos pelo seu trabalho, mas percebe-se que a recompensa almejada e recebida pelos funcionários é a recompensa psíquica, não pecuniária.

E4 Eu acho que valorização é a pessoa ser convidada para fazer uma função fora da empresa, representando ela. Eu por exemplo, fui valorizado pelo convite da chefe-geral para desempenhar essa função. [...] Então, eu acho que sim, sou valorizado.

\section{- Apoio à ação intraempreendedora na instituição}

Quando questionados se a organização apoiava as iniciativas empreendedoras, todos os entrevistados informaram que possuem apoio para inovar, sendo isso uma característica fundamental em uma empresa de pesquisas. Tal apoio, segundo os funcionários, é importante para tornar o ambiente mais salutar e apropriado à ação inovadora. Os trechos a seguir evidenciam tal afirmação:

E3 Eu acho que porque nós somos uma empresa de inovação, a gente é incentivado constantemente a fazer isso.

E5 Nós temos uma gestão que estimula muito isso. Temos reuniões perió- 
dicas para colocar as ideias e dificuldades que estamos tendo no trabalho e aceitamos sugestões inovadoras para os problemas.

E7 A gente tem que inovar a cada dia. Então, quando esse incentivo vem da chefia, dizendo que a gente pode arriscar e pode errar tentando fazer certo, eu acho que isso é salutar, isso é um incentivo. E a gente tem essa possibilidade aqui.

\section{- Estímulo à autonomia dos colaboradores}

A autonomia para tomar iniciativas é um fator muito importante para os intraempreendedores. No caso da Embrapa, ela apresentou o seu perfil de instituição de pesquisa, em que a autonomia é fundamental para o desenvolvimento das atividades diárias do órgão. Dessa forma, quando questionados sobre o tema, os entrevistados foram enfáticos ao afirmar que a autonomia não só existe como é cobrada pelos seus superiores.

E1 Temos bastante autonomia e isso é fundamental. O nosso presidente, quando eu assumi, fez questão de me dizer que eu não deveria ficar no dia a dia, e sim que eu devia pensar estrategicamente. E isso pra mim foi muito libertador.

E2 Claro que sim, temos autonomia e somos incentivados a fazermos isso.

E3 Temos bastante autonomia para criar, mas claro que isso passa por um processo interno de convencimento dos pares.

Percebe-se, portanto, que a autonomia deve ser estimulada, pois não existe inovação sem risco e, para se correr risco, os servidores precisam ter autonomia para tomar decisões.

\section{- Política de permanência limitada nos cargos}

A política de rotação dos cargos foi citada na Embrapa como uma prática que auxilia a inovação e o empreendedorismo. Lá existe um processo para escolha do chefe geral das unidades a cada três anos. $\mathrm{O}$ escolhido em um processo nacional pode ter apenas uma recondução por igual período, o que acaba gerando uma rotação natural nos cargos de chefia de toda a estrutura. Os funcionários entrevistados concordaram que tal prática é fundamental para estimular uma nova visão acerca dos problemas dos setores e fomentar a inovação na resolução de tais problemas.

El Aqui na Embrapa essa oxigenação eu acho que ajudou muito, justamente pela mudança, trazendo um pensamento diferente, uma nova forma de lidar com os problemas, além de uma participação diferente dos funcionários.

E18 A rotação de cargos é bem importante porque ela ajuda a evitar os vícios. Ter sempre cabeças novas com ideias novas ajuda a ter outros olhares no processo.

E19 Acho fundamental, isso acontece aqui e eu acho que tem que ser mantido. 


\section{- Reuniões periódicas abertas com grupos de servidores}

Quando se tratou acerca da comunicação, o ruído foi lembrado como algo natural e possível de se corrigir. De toda forma, os entrevistados afirmaram que os meios de comunicação em si funcionam bem, embora haja ruídos muitas vezes gerados, por exemplo, por e-mails mal escritos ou mal interpretados. Nesse contexto, uma das entrevistadas lembrou que o canal de comunicação aberto pela chefia geral, que realiza reuniões periódicas com os servidores, é um exemplo de transparência e que contribui para a eliminação de ruídos.

E6 Nós temos muita liberdade de conversar com os colegas e com as chefias. [...] A comunicação é algo importante. [...] Aqui a chefia inovou e agora nos temos reuniões com grupos de funcionários para ver como que tá a situação, se tem havido problemas e tal. Isso eu acho muito legal, ter um contato mais direto.

\section{- Prática de tolerância a erros}

A tolerância a erros é uma importante prática que incentiva o intraempreendedorismo, de modo que, ainda que haja erro, as informações devem fluir de forma normal na organização. Assim, na Embrapa, percebeu-se que a tolerância a erros é realmente um fator que auxilia o processo de pesquisa. Todos os entrevistados fizeram a resalva de que, às vezes, erram porque correm riscos e, sem risco, não há inovação nem pesquisa, conforme eles explicitaram através de algumas de suas falas:

E4 Temos tolerância, porque eu acho que tem que fazer as coisas, porque o pior é não fazer, e só não erra quem não faz.

E5 Eu penso que o projeto de pesquisa nunca dá errado. Ele sempre dá certo. Porque mesmo que dê errado, isso já é um resultado. Então, sob esse foco, o erro é tolerado na empresa.

E6 Temos tolerância e isso te ajuda a arriscar. [..] E na pesquisa é muito assim. É claro que a gente tem que fazer as coisas de acordo com os métodos científicos, de modo a evitar erros e apontar quais as possíveis dificuldades e como contorná-las.

\section{- Parcerias com a iniciativa privada}

As entrevistas também revelaram um fator importante no sentido de inserir o empreendedorismo e a inovação na organização. Trata-se do novo marco legal de ciência e tecnologia, ${ }^{1}$ que foi citado pelos entrevistados como uma forma muito eficiente para atrair empreendedores para o serviço público. Tal dispositivo legal permitirá que organizações de pesquisa como a Embrapa compartilhem os seus laboratórios e equipes com as empresas para fim de pesquisa, de forma remunerada. Isso ocasionará uma aproximação entre os institutos públicos de pesquisas e as empresas privadas, em prol da inovação científica, conforme pode ser visto a seguir em trechos retirados das entrevistas:

El Eu acredito que o novo marco legal de ciência e tecnologia vai fazer 
uma revolução para nós, porque ele vai facilitar muito a nossa participação como incubadora de empresas.

E2 Agora nós temos um novo marco legal de ciência e tecnologia que é um exemplo de que a gente pode atrair empreendedores para o ambiente interno.

Assim, embora seja um dispositivo que se aplica somente a instituições de pesquisa, esse novo marco legal é um exemplo de como a legislação pode ser utilizada em prol da modificação de estruturas arraigadas e cristalizadas no serviço público.

\section{Dificuldades para o intraempreendedorismo na Embrapa}

Como mencionado na fase introdutória do presente artigo, várias são as dificuldades e barreiras para a introdução de uma cultura intraempreendedora no serviço público. Na Embrapa, embora seja uma instituição intimamente ligada à pesquisa e à inovação, fatores intrínsecos ao empreendedorismo, essas dificuldades também aparecem.

A burocracia excessiva, por exemplo, foi apontada como um dos principais desafios para se ter uma cultura que favoreça o intraempreendedorismo em organizações do setor púbico. Quando questionados sobre esses principais desafios, os entrevistados responderam assim:

E2 Eu vejo que são as amarras burocráticas, pois elas inibem essa cultura empreendedora, porque as pessoas vão desistindo com as experiências que elas têm, de não conseguir fazer as coisas.

E3 A estrutura mais rígida de uma empresa pública faz com que nós tenhamos o desafio de nos reinventarmos. Eu vejo que hoje o que mais está na pauta é como dar um mínimo de autonomia e de flexibilidade nos trabalhos.

Também houve a reclamação de que a burocracia e o apego às normas e regulamentos desestimulam a cultura empreendedora, de modo que somente com muita persistência, característica fundamental de um intraempreendedor, é possível se destacar e fazer algo diferente e inovador.

E3 Eu acho que as amarras institucionais, sobretudo de licitações e do grau de liberdade com que você pode negociar alguma parceria impedem um maior empreendedorismo. Isso do ponto de vista do arcabouço institucional. Já com relação à cultura, eu acho que esse arcabouço determinou uma cultura mais burocrática, mais de zona de conforto.

E8 A burocracia e a impossibilidade de reconhecer os esforços individuais também desestimulam bastante.

Outra questão bastante comentada como um desafio na Embrapa foi a de fazer as pessoas se sentirem participantes e conhecedoras do negócio principal da organização. Para os entrevistados, a resolução desse problema poderia alavancar o intraempreendedorismo na empresa. 
E6 Eu acho que tem fazer com que as pessoas participem, fazer com que elas saibam porque elas estão fazendo aquilo e se sentirem parte do processo.

E7 Temos que fazer com que as pessoas se enxerguem dentro do processo produtivo.

Essa questão também é defendida por autores como Wright, Pandey e Moynihan (2012) e Rayner, Lawton e Williams (2012). Segundo eles, o fato de o funcionário saber que seu papel está inserido num contexto maior, que seria o atendimento ao público, faria que o funcionário trabalhasse de forma eficiente, justamente por saber que está lidando com o bem público, o que seria suficiente para lhe gerar motivação.

Já acerca do processo de contratação de servidores, houve posicionamentos afirmando que deveria haver mudanças na forma de acesso por concurso público, uma vez que atualmente é muito difícil aferir o nível do perfil intraempreendedor através das provas, devido ao caráter subjetivo que este tipo de aferição poderia trazer.

E5 O concurso público é uma loteria. Pode ter gente excelente tecnicamente e impossíveis de trabalhar junto..

Na Embrapa há também um consenso de que, embora necessária e importante para evitar fraudes, a Lei n.8.666 (lei de licitações e contratos) representa um entrave nas atividades do serviço público.

E3 Eu acho fundamental rever a lei de licitações para a pesquisa.

E7 A lei de licitações é um problema sério. Ela diz que traz economia, mas quem tá fora não tem noção do quanto é custoso. Você tem um setor específico para licitações, um volume de papel, a qualidade dos produtos que às vezes, devido ao menor preço, acaba deixando a desejar.

Por fim, a resistência dos sindicatos ao intraempreendedorismo também foi citada como barreira a ser transposta pela organização.

E3 Há muitas resistências, não só do sindicato, mas daquelas pessoas que, por ventura, seriam afetadas.

E8 Eu acho que o intraempreendedorismo influenciaria diretamente e positivamente, mas eu acho que o sindicato não permitiria e lutaria contra isso.

\section{Considerações finais}

Após a análise das entrevistas e o confronto com a literatura sobre o assunto, foi possível elencar as principais práticas intraempreendedoras utilizadas na Embrapa, quais sejam, o estímulo ao comportamento intraempreendedor através de exemplos e desafios, recompensando o comportamento diferenciado; o apoio à ação intraempreendedora na instituição; o estímulo à autonomia dos colaboradores; a política de permanência limitada nos cargos; um programa de reuniões periódicas abertas com grupos de servidores; a prática de tolerância a erros e as parcerias com a iniciativa privada. 
Esse conjunto de práticas intraempreendedoras, segundo os entrevistados, tem auxiliado a Embrapa a se manter como uma instituição de excelência e de inovação tecnológica no setor pesquisas para a cultura de suínos e aves, colocando a empresa em um patamar internacional nesse segmento.

Acerca das diversas dificuldades ao intraempreendedorismo apresentadas pelos entrevistados, o aparato legal de contratos e licitações, além da lei que rege os concursos públicos foram apontados como grandes dificultadores para se ter uma cultura empreendedora no serviço público.

A burocracia e suas disfunções, todavia, obtiveram papel de destaque, de modo que as seguintes sugestões foram apresentadas para tentar diminuir arcabouço burocrático: mapear e redesenhar os processos de forma a eliminar etapas de cunho puramente burocrático; automatizar os processos de forma a eliminar necessidade de assinaturas, carimbos e impressões, tornando os documentos totalmente digitais; descentralizar o processo decisório, dando mais autonomia às gerências de médio porte.

De qualquer forma, a despeito do fato de que as organizações públicas sejam reconhecidas como muito peculiares no que diz respeito à hierarquia excessiva, apego às regras e à burocracia, Kearney e Morris (2015) afirmam que há uma necessidade crescente de abordagens empreendedoras na administração pública, pois o ambiente externo de muitas organizações do setor público pode ser caracterizado como cada vez mais turbulento, impondo uma dinâmica e complexa condição de gestão para os administradores públicos, de modo que o caso da Embrapa, com seus resultados, se mostra um exemplo a ser seguido.

Como sugestões para futuros trabalhos, acredita-se que o estudo das práticas intraempreendedoras poderia se feito em outra instituição pública para que seus resultados sejam confrontados com os aqui apresentados.

\section{Nota}

1 Lei n.13.243, de 11 de janeiro de 2016, a que dispõe sobre medidas de incentivo à inovação e à pesquisa científica e tecnológica no ambiente produtivo, objetivando a capacitação tecnológica, a autonomia tecnológica e o desenvolvimento do sistema produtivo nacional e regional do país.

\section{Referências}

ANTONCIC, J. A.; ANTONCIC, B. Employee satisfaction, intrapreneurship and firm growth: a model, Industrial Management \& Data Systems, v.111, n.4, p.589-607, 2011.

BARUAH, B.; WARD, A. Metamorphosis of intrapreneurship as an effective organizational strategy. International Entrepreneurship and Management Journal, v.10, n.1, p.23-35, 2014.

BRASIL. Lei n.8.666, de 21 de junho de 1993. Diário Oficial da União, Poder Legislativo, Brasília, DF, 22 jun. 1993. 
EMBRAPA, Empresa Brasileira de Pesquisa Agropecuária. Encarte Demonstrativo. MAPA, Agosto de 2015.

GIL, A. C. Métodos e técnicas de pesquisa social. São Paulo: Atlas, 1999.

GOMES, R. K;; LAPOLLI, E. M. O intraempreendedorismo no serviço público: modismo ou oportunidade de melhoria? In: CIKI - IV CONGRESSO INTERNACIONAL DE CONHECIMENTO E INOVAÇÃO, Loja, Equador. Anais..., Loja: Ciki, 2014. p.894-918.

GOODALE, J. C. et al. Operations management and corporate entrepreneurship: The moderating effect of operations control on the antecedents of corporate entrepreneurial activity in relation to innovation performance. Journal of Operations Management, v.29, n.1, p.116-27, 2011.

HARO, S. G.; CORREA, J. A. A.; POZO, E. C. Differentiating the effects of the institutional environment on corporate entrepreneurship. Management Decision, v.49, n.10, p.1677-93. 11/2011.

HASHIMOTO, M. O que é intraempreendedorismo. 2012. Disponível em: <http:// www.innoscience.com.br/correio/15.pdf>.

KEARNEY, C.; HISRICH, R.; ROCHE, F. A conceptual model of public sector corporate entrepreneurship. International Entrepreneurship And Management Journal, New York, v.1, n.4, p.295-313, maio 2007.

Change Management Through Entrepreneurship In Public Sector Enterprises. Journal of Developmental Entrepreneurship, v.15, n.4, p.415-37, dez. 2010.

KEARNEY, C.; MORRIS, M. H. Strategic renewal as a mediator of environmental effects on public sector performance. Small Business Economics, v.45, n.2, p.425-45, fev. 2015.

KURATKO, D. F.; HORNSBY, J. S.; COVIN, J. G., Diagnosing a firm's internal environment for corporate entrepreneurship. Business Horizons, v.1, n.57, p.37-47, 2014.

LIMA, P. D. B. A excelência em gestão pública: A trajetória e a estratégia do Gespública. Rio de Janeiro: Qualitymark, 2007.

MATIAS-PEREIRA, J. Curso de Gestão Estratégica na Administração Pública. São Paulo: Atlas, 2012.

MEYNHARDT, T.; DIEFENBACH, F. E. What Drives Entrepreneurial Orientation in the Public Sector? Evidence from Germany's Federal Labor Agency. Journal of Public Administration Research and Theory, v.22, n.4, p.761-92, abr. 2012.

OLSZEWSKA, A. Students' perceptions and attitudes towards entrepreneurship, a cross- program and cross-cultural comparison. Journal Of Business \& Management, Paquistão, p.257-68. jul. 2014.

PESSOA, E.; OLIVEIRA, C. N. O. Perfil intraempreendedor: um estudo inicial em Funcionários da Infraero-sede. Revista do Serviço Público, Brasília, v.4, n.57, p.507-29, out./dez. 2006.

PIHIE, Z. A. L.; BAGHERI, A.; SANI, Z. H. A. Exploring regulatory focus, entrepreneurial intention, Self-Efficacy and Entrepreneurial Skills Among Malaysian Higher Learning Institution Students. In: Proceedings of the $7^{\mathrm{TH}}$ European Conference On Innovation And Entrepreneurship, Portugal. Escola Super Gestao \& Tecnologia, 2012. v.1, p.430-7. 
PINCHOT, G. III. Intrapreneuring: porque você não precisa deixar a empresa para tornar-se um empreendedor. Trad. Nivaldo Montingelli Jr. São Paulo: Harbra, 1989.

RAYNER, J.; LAWTON, A.; WILLIAMS, H. M. Organizational Citizenship Behavior and the Public Service Ethos: Whither the Organization? Journal of Business Ethics, v.106, n.2, p.117-30, 2012.

SADLER, R. J. Corporate entrepreneurship in the public sector: the dance of the chameleon. Australian Journal of Public Administration, Austrália, v.2, n.59, p.25-43, jun. 2000 .

SCHUMPETER, J. A. A Teoria do desenvolvimento econômico: uma investigação sobre lucros, capital e crédito, juros e ciclo econômico. 2.ed. São Paulo: Nova Cultural, 1985.

SEVERINO, J. A. Metodologia do trabalho cientifico. 2.ed. São Paulo: Nova Cultura, 1985.

SIXSMITH, A.; MOONEY, G. Entrepreneurship and entrepreneurs in small innovative Australian firms. In: Proceedings of the $19^{\text {th }}$ International Business Information Management Association Conference. Barcelona; Spain; 12 November 2012 through 13 November 2012. v.1, 2012, p.154-63.

SUNDIN, E.; TILLMAR, M. A Nurse and a Civil Servant changing institutions. Small Business Economics. Scandinavian Journal of Management, v.24, n.2, p.113-24, jun. 2008 .

TOSTERUD, R. Entrepreneurship and the public sector. Current Politics And Economics Of The United States, Commack, NY, v.3, n.1, p.143-58, mar. 2000.

TRIVIÑOS, A. N. S. Introdução à Pesquisa em Ciências Sociais: A Pesquisa Qualitativa em Educação. São Paulo: Atlas, 2012.

VALADARES, J. L.; EMMENDOERFER. A. Incorporação do empreendedorismo do setor público: reflexões baseadas no contexto brasileiro. Revista de Ciências da Administração, Florianópolis, v.17, n.41, p.82-98, 2015.

VALADARES, J. L. et al. O fenômeno do empreendedorismo público: um ensaio sobre a aplicabilidade desse construto na administração pública brasileira. In: XXXVI ENCONTRO DA ANPAD. Rio de Janeiro: Anpad, 2012.

VALSANIA, S. E.; MORIANO, J. A.; MOLERO, F. The effect of intrapreneurial experience on corporate venturing authentic leadership and intrapreneurial behavior: Cross-level analysis of the mediator effect of organizational identification and empowerment. International Entrepreneurship and Management Journal, New York, v.10, n.1, p.1-22. 7 ago. 2014.

WRIGHT, B. E.; PANDEY, S. K.; MOYNIHAN, D. P. Pulling the Levers: Transformational Leadership, Public Service Motivation, and Mission Valence. Public Administration Review, v.72, n.2, p.206-15, abr. 2012.

WYK, R. van; ADONISI, M. Antecedents of corporate entrepreneurship. The South African Journal of Business Management, South Africa, v.43, n.3, p.65-79, set. 2012.

ZAHRA, S. A.; WRIGHT, M. Entrepreneurship's next act. Academy Of Management Perspectives, v.25, n.4, p.67-83, 1 nov. 2011. The Academy of Management. DOI: 10.5465/amp. 2010. 0149. 
RESUMO - O fenômeno do intraempreendedorismo tem chamado a atenção de pesquisadores e estudiosos ao redor do mundo, especialmente nas últimas duas décadas. A maior parte desses estudos é realizada em empresas do setor privado, devido à intrínseca natureza competitiva do seu ambiente. No setor público, todavia, os estudos sobre o intraempreendedorismo ainda encontram-se escassos ou em fases muito incipientes. Tal ambiente público, contudo, necessita, de maneira premente, de uma estratégia intraempreendedora que estimule a aceitação de riscos, responsabilidades e desafios, eliminando o excesso de formalismo. Portanto, o objetivo deste artigo é estudar as práticas intraempreendedoras utilizadas em uma instituição federal de pesquisa, bem como as principais barreiras para se ter uma visão intraempreendedora nessa organização. Para alcançar tal objetivo, foi realizada uma pesquisa aplicada, exploratória e descritiva, com abordagem qualitativa e auxílio de um estudo de caso. Como resultados, foi possível verificar que as principais práticas utilizadas na organização estão ligadas a maior autonomia dos funcionários, recompensas financeiras e não pecuniárias, permanência limitada nos cargos e a tolerância a erros. Além disso, foram apresentadas as dificuldades nesse processo, sendo o excesso de burocracia e o apego às normas e regulamentos os principais entraves ao intraempreendedorismo.

PALAVRAS-CHAVE: Empreendedorismo, Intraempreendedorismo, Gestão pública.

ABSTRACT - Intrapreneurship has attracted the attention of researchers and scholars around the world, especially in the last two decades. Most of these studies are conducted in private companies because of the intrinsic competitive nature of their environment. In the public sector, however, studies on intrapreneurship are still scarce or at very early stages. The public environment, however, urgently needs an intrapreneurial strategy that encourages the acceptance of risks, responsibilities and challenges, eliminating the excess of formalism. Therefore, the focus of this article is to study the intrapreneurial practices of a federal research institution, as well as the main barriers to having an intrapreneurial management in this organization. To achieve this goal, an applied, exploratory and descriptive research was carried out, with a qualitative approach and a case study. As a result, it was possible to verify that the main practices used in the organization are linked to greater employee autonomy, financial and non-pecuniary rewards, limited time in one position and tolerance to errors. In addition, the difficulties in this process are presented, with red tape and adherence to norms and regulations being the main obstacles to intrapreneurship.

KEYWORDS: Entrepreneurship, Intrapreneurship, Public administration.

Édis Mafra Lapolli é doutora e mestre em Engenharia de Produção pela Universidade Federal de Santa Catarina (UFSC), com pós-doutorado em Sistemas de Informação pela Université de Montpellier II (Scien. et Tech. Du Languedoc - France). Engenheira civil, professora do Programa de Pós-Graduação em Engenharia e Gestão do Conhecimento e coordenadora da área de Gestão do Conhecimento (UFSC). @ - edismafra@gmail.com

Roberto Kern Gomes é doutorando do Programa de Pós-Graduação em Engenharia e Gestão do Conhecimento na Universidade Federal de Santa Catarina (UFSC), com mestrado em Administração pela Universidade do Estado de Santa Catarina e especialização em Administração Global pela Universidade Independente de Lisboa.

@ - robertokerngomes@gmail.com 
Recebido em 3.7.2017 e aceito em. 31.7.2017.

I, II Programa de Pós-Graduação em Engenharia e Gestão do Conhecimento, Universidade Federal de Santa Catarina, Florianópolis, Santa Catarina Brasil. 